\title{
From Crisis to Opportunity and Back Again: Is There a Response Shift at the Population-Level regarding Geriatric Training in Lebanon?
}

\author{
Romy Nehme1, Lama R. Bazzi2, Christina P. C. Borba ${ }^{1,3,4}$, Zeina N. Chemali1 ${ }^{1,3,4^{*}}$ \\ ${ }^{1}$ Department of Psychiatry, Massachusetts General Hospital, Boston, USA \\ ${ }^{2}$ Division of Forensic Psychiatry, Case Western Reserve University Hospitals, Cleveland, USA \\ ${ }^{3}$ The Chester M. Pierce, MD Division of Global Psychiatry, Massachusetts General Hospital, Boston, USA \\ ${ }^{4}$ Harvard Medical School, Boston, USA \\ Email: zelchemali@partners.org
}

Received 13 January 2014; revised 9 April 2014; accepted 28 April 2014

Copyright (C) 2014 by authors and Scientific Research Publishing Inc.

This work is licensed under the Creative Commons Attribution International License (CC BY). http://creativecommons.org/licenses/by/4.0/

(c) (i) Open Access

\begin{abstract}
Between crisis and opportunity, old age has many faces in Lebanon. While old age was first seen as a time of wisdom, the current trend accentuated by migration and the economic crisis sets a challenge for the Lebanese elder; they may be left behind unless something is done in all communities at a national level. In this short communication, we attempt to broaden the scope of thinking about training programs to target population-shift and create a true change. We reflect on our results as an intermediate outcome of public health interventions. We suggest that it may be worthwhile to evaluate population-shifts further and base the success of an intervention on measures of Health Related Quality of Life through the response-shift created by such national public health programs.
\end{abstract}

\section{Keywords}

Capacity Building, Public Health, Elderly, Training, Quality of Life

\section{Introduction}

The Lebanese elder population currently represents 8.5 percent of the entire Lebanese population [1]. Most of them usually live in their homes, and are often taken care of by their families [2]. However, with a high unemployment rate, many young Lebanese men and women leave the country to make a living, leaving the aging po-

*Corresponding author.

How to cite this paper: Nehme, R., et al. (2014) From Crisis to Opportunity and Back Again: Is There a Response Shift at the Population-Level regarding Geriatric Training in Lebanon? Advances in Aging Research, 3, $109-112$. 
pulation without caregivers and incredibly vulnerable. Nowadays, the Lebanese aging population is drained by current times, which further increases old age poverty [2]. Not to mention that, as the Lebanese elderly population grows, so do the unfamiliar challenges that lie ahead. With many caregivers working abroad, the elderly, especially those with dementias, face issues such as testamentary capacity and guardianship without much guidance. Interventions yielding to careful mental health and capacity evaluations are rare in Lebanon. Only the most privileged elders know about advance directives and end-of-life measures are rarely a debated topic. Moreover, governments do not make the hurdles above easier. In fact, governments continue to react by cutting funds to programs related to geriatric care, painting the elderly as a burden to society, and denying the means to tap the potential of healthy old age. This can only mean negative perception to ageism, bringing old age to a stage of crisis. In addition, this shift in discourse may create fear in the population who once viewed elders as a source of wisdom, respected their advice and looked forward to including them in everything they did. Those fears of "old age" can further lower the quality of life of the elderly, as well as young people contemplating their own old age to come one day.

In this report, the authors take the time to ponder on needed population shift as new elder/geriatric training programs are built in specific regions of the world, with intent to create the change at a population-level regarding ageism [3]. In this task, the authors also reflect on their results as an intermediate outcome in public health interventions.

\section{Defining Response Shift}

Response shift refers to a change in the meaning of one's evaluation of a construct as a result of a change in one's internal standards of measurements, a change in one's values, or a change in one's definition of the construct [4]. Population-level shift occurs when a large proportion of the population experiences the same shift simultaneously as a socially significant change or event.

\subsection{Past Experiences of Response Shifts}

We will consider two examples specific to Lebanon whose effects lead to population-level response shifts that modified Health Related Quality of Life (HRQL): the 2006 war in Lebanon and the Lebanese smoking ban. These examples serve two purposes. First, they assert that population shifts are possible and have happened before. Thus, an initiative to produce a positive response shift may be effective. Second, they illustrate that positive population level shifts might not be apparent at first glance. Nevertheless, a deeper analysis could reveal immense progress on the wellbeing for when an initiative to produce a positive response shift appears ineffective, one would first need to revise the metric being evaluated before jumping to conclusions.

The 2006 Lebanon war provided an example of a traumatic event affecting a large population. Elders in Lebanon are a vulnerable group during a war, regardless of what part of the country they reside in. During the 2006 war, a majority of Lebanon's residents reported increased symptoms of Post Traumatic Stress Disorder (PTSD) [5], depression, frailty, malnutrition and lack of self care [6]. However, positive effects have also been observed including resilience, closer relationships with others, tighter bonds with neighbors, increased compassion and spirituality, empathy and help among refugees or internally displaced people from the eldest to the youngest [7]. Those elders who experienced hope and spirituality experienced lower anxiety and depression, greater satisfaction with life and better health [7] [8]. Response shift in this example was considered at a population-level as everyone shifted at the same time leading to a social trend, after a national catastrophe and in the health status of the whole population.

The smoking ban in Lebanon provided another example of population-level response shift. Smoking ban is likely to induce a population-level shift including wellbeing, prosperity, diet and social norms though affecting the prevalence of smoking as a social pressure. A substantial proportion of smokers (81\%) started perceiving little social approval for their smoking (this shift in perception referred to as denormalization), would have fewer places to smoke [9] and regretted smoking ever [10]. This denormalization triggered a reconceptualization of HRQL to include the negative effects of smoking.

\subsection{Reflecting on Training Assessment}

Taken the two examples above to assess the impact of a training initiative on response shift could be based on pre- and post-workshop and training session tests [11]. Such an approach would hinge on quantifying only the 
knowledge acquired by the participants during the training sessions, and might fail to represent their knowledge/experience in elderly care. One would seek to understand whether or not the assessment captured the features of a potential response shift: the goal of the initiative would be not to increase knowledge, but to foster a general understanding and encourage a practical approach to elderly care. In this respect, the results of a preand post-test could only be relevant in determining how effective the training sessions were in conveying information to the participants. One would not jump to conclusions regarding the population level shift, regardless of whether or not the test showed that the training had a positive impact on trainees.

Furthermore, the dataset provided by the pre- and post-test presented a cross sectional assessment. A long-term analysis would necessarily require a sequence of follow-up evaluations timed accordingly. Those should not only focus on detecting an increase of knowledge and confidence, but would also include long term evaluation questions assessing the impact of the training in implementing policy, clinical, education and/or research activities in the communities.

\subsection{Reflecting on Training Conditions}

We expect that response-shifts at the level of the Lebanese population would be better achieved if the cared-for cases were "organic" (i.e. "home-grown"). For example, and drawing on our own experience in the field, it would be beneficial to allow the social workers under training to get to know the elders they care for better, and incentivize them to work specifically in the geriatric field [3]. Population-shift in geriatric care in Lebanon would more likely occur and positively alter the HRQL capitalizing we capitalize on human bond, compassion and support to build networks and community programs to serve elders. Since family and person-to-person bonds are the country's forte [12], capitalizing on family dynamics in Lebanon would likely increase HRQL.

Also, while planning the trainings, many factors ought to be taken into consideration. Beyond general logistics (e.g. weather, number of participants, holiday schedule...) trainers would need to account for the political and cultural contexts in some societies [13]. This issue has special relevance for older adults in Lebanon as they endured a 16 year civil war and weathered many sectarian conflicts. Identity matching based on religious or political affiliation might offer an opportunity for collecting data when conducting surveys or focus groups. Such a matching would encourage the participants to open up, create a trusting atmosphere and help establish a bond based on a perceived shared identity.

The legal and other implications of aging are many and complex, and implementing resources to address potential concerns need to be a part of programs targeting geriatric care. Given this, the authors would like to caution that specific interpretations of population-level response shift would add complexity to the program selection. Nevertheless, geriatric HRQL in the Lebanese population would not occur without taking these factors into consideration. These factors are mandatory in the selection and interpretation of preferential functions for HQOL economic applications such as pushing a bill covering elders' medical services and allowing for continuous medical insurances and elder pensions and benefits.

\section{Conclusion}

In this short communication, we have tried to broaden the scope of thinking about training programs abroad to target population-shift creating a true change. Response shift occurs at the level of the population when a large proportion of the population experiences the shift simultaneously and as a core group, and when the cause of the shift becomes socially a significant event or trend. Such catalysts are often qualitative and differ highly from placing numbers and tags on interventions as we often do with our quantitative measures. When we measure the impact of an intervention, we do not know whether a specific training or campaign has resulted in a response shift unless we allow ourselves to ask the right questions and seek out the answers on the field. We would not know instantaneously whether a shift had any bearing on the conduct and interpretation of research. We caution the reader to question at a deeper level the impact of an awareness campaign and to observe for shifts. In posing this debate, we suggest that it might be worthwhile to further evaluate population-shifts and measure not only through ear and mouth a specific training but base the success of an intervention on measures of HRQL in large populations through the response-shift created by such national public health programs.

\section{References}

[1] United Nations, Department of Economic and Social Affairs, Population Division (2013) World Population Prospects: 
The 2012 Revision. DVD Edition.

[2] Chemali, Z., Chahine, L.M. and Sibai, A.M. (2008) Older Adult Care in Lebanon: Towards Stronger and Sustainable Reforms. Eastern Mediterranean Health Journal, 14, 1466-1476.

[3] Bazzi, L., Borba, C., Carney, J. and Chemali, Z. (2013) Capacity Building in Alzheimer’s Disease (AD): Lessons Learned from a Pilot Study in Six Distinct Areas of Lebanon. Journal of Scientific Research \& Reports, 3, 185-203.

[4] Sprangers, M.A. and Schwartz, C.E. (1999) Integrating Response Shift into Health-Related Quality of Life Research: A Theoretical Model. Social Science \& Medicine, 48, 1507-1515. http://dx.doi.org/10.1016/S0277-9536(99)00045-3

[5] Farhood, L.F. and Dimassi, H. (2012) Prevalence and Predictors for Post-Traumatic Stress Disorder, Depression and General Health in a Population from Six Villages in South Lebanon. Social Psychiatry and Psychiatric Epidemiology, 47, 639-649. http://dx.doi.org/10.1007/s00127-011-0368-6

[6] Farhood, L.F., Chaaya, M. and Saab, B.R. (2010) Detainment and Health: The Case of the Lebanese Hostages of War. International Journal of Mental Health Nursing, 19, 83-91. http://dx.doi.org/10.1111/j.1447-0349.2009.00653.x

[7] Nuwayhid, I., Zurayk, H., Yamout, R. and Cortas, C.S. (2011) Summer 2006 War on Lebanon: A Lesson in Community Resilience. Global Public Health, 21, 1-15.

[8] Jawad, M.H., Sibai, A.M. and Chaaya, M. (2009) Stressful Life Events and Depressive Symptoms in a Post-War Context: Which Informal Support Makes a Difference? Journal of Cross-Cultural Gerontology, 24, 19-32. http://dx.doi.org/10.1007/s10823-008-9059-5

[9] Hammond, D., Fong, G.T., Zanna, M.P., Thrasher, J.F. and Borland, R. (2006) Tobacco Denormalization and Industry Beliefs among Smokers from Four Countries. American Journal of Preventive Medicine, 31, 225-232. http://dx.doi.org/10.1016/j.amepre.2006.04.004

[10] Fong, G.T., Hammond, D., Laux, F.L., Zanna, M.P., Cummings, K.M., Borland, R., et al. (2004) The Near-Universal Experience of Regret among Smokers in Four Countries: Findings from the International Tobacco Control Policy Evaluation Survey. Nicotine and Tobacco Research: Official Journal of the Society for Research on Nicotine and Tobacco, 6, S341-S351. http://dx.doi.org/10.1080/14622200412331320743

[11] Howard, J.S., Mattacola, C.G., Howell, D.M. and Lattermann, C. (2011) Response Shift Theory: An Application for Health-Related Quality of Life in Rehabilitation Research and Practice. Journal of Allied Health, 40, 31-38.

[12] Hospers, A.P., Chahine, L.M. and Chemali, Z. (2007) Health Care Delivery Systems for Older Adults: How Do the Netherlands and Lebanon Compare? Social Science and Medicine, 65, 1979-1985. http://dx.doi.org/10.1016/j.socscimed.2007.08.033

[13] Abdulrahim, S., Ajrouch, K.J., Jammal, A. and Antonucci, T.C. (2012) Survey Methods and Aging Research in an Arab Sociocultural Context-A Case Study from Beirut, Lebanon. Journal of Gerontology. Series B: Psychological Sciences and Social Sciences, 67, 775-782. http://dx.doi.org/10.1093/geronb/gbs083 